\title{
Understanding off-site readiness in Indian construction organisations
}

\section{Abstract}

\section{Purpose}

This paper presents a bespoke model for understanding off-site construction (OSC) readiness among Indian construction organisations. This model presents 17 variables for discussion, the results from which help support OSC strategic decision making.

\section{Design/Methodology/Approach}

Factor analysis was used to investigate the relationship between variables in order to group them into factors. After identifying 26 different variables, these were reduced to 17 using factor analysis and categorised into four groups. Descriptive statistical analysis and factor analysis using SPSS was used to develop a hierarchy of factors that affect OSC readiness in India. These findings were reinforced by five domain experts to support the results.

\section{Findings}

Minimising on-site duration, ensuring cost and time certainty and transportation issues were identified as the three most important factors. Whereas, lack of guidance and scepticism were among the lowest factors affecting the Indian OSC sector.

\section{Practical Implications}

The proffered off-site construction readiness model offers OSC practitioners an ability to assess the OSC readiness of construction organisations in India. This includes the evaluation and benchmarking of processes in both strategic and operational phases; including highlighting areas of concern and scope for further development (to achieve optimal advantage of OSC methods).

\section{Originality/Value}

Originality rests with the use of factor analysis and descriptive statistical analysis to study the influence of different construction-related factors and variables on the OSC sector in India. This impact readiness model is context-specific to the Indian OSC sector - providing a unique insight into the causal factors and dependencies that can affect the adoption and uptake of modern methods of construction in India.

\section{Limitations}

This research is specifically focused on OSC within the Indian construction sector. As such, data collection, propagation and analysis should be constrained to the population context regarding inference, generalisability and repeatability.

\section{Keywords}

Offsite Construction (OSC); Indian Construction industry; Housing; Modular Construction; Strategy; Process. 


\section{Introduction}

India is the second most populated country in the world, with an estimated 1.31 billion people (UN report, 2015); with a corresponding construction sector that is expected to be the third largest by 2030 (KPMG, 2016). The sector is largely driven by the government of India, with investments on core urban infrastructure projects (Maniar, 2010). Moreover, India is expected to accommodate six megacities with a population of above ten million by 2030 (NITI Aayog, 2018), and this expansion is expected to grow Gupta et al., (2009).

Parallel to this development, the Indian construction industry is gradually becoming more sustainable, where over the last decade in particular has witnessed significant growth in the green footprint in India (Arif et al., 2012). Coincidentally, OSC sustainability has also been prioritised among the top issues to meet the sustainable development agenda 2030 (Goulding et al., 2015). However, the increasing housing and infrastructure needs in India are challenging sustainable performance (Shrivastava and Chini, 2011); which anecdotally, can be attributed to a number of factors (Umar et al., 2017). Notwithstanding this, India is expected to facilitate its growing population, which places and increasing need for infrastructure (Arif et al., 2012b).

The pivotal challenge faced here is delivering the infrastructure required to meet demand. Conventional approaches have been beset with major challenges, not least meeting quality and speed of delivery. Given these issues, this paper highlights the current and potent impact of OSC in meeting these challenges. In doing so, it analyses the variables which affect OSC readiness in the Indian construction sector in order to understand and improve it. An off-site readiness model is presented for discussion.

\section{Offsite Construction: Contextual Developments}

The move towards OSC in Architecture, Engineering and Construction (AEC) is continuing to gain momentum (Goulding and Arif, 2013; Goulding and Pour Rahimian, 2019; McGrawHill, 2011). This resurgence has been proffered as a new paradigm for addressing AEC demand. Whilst terminologies and definition of OSC in multiple contexts and backgrounds have been espoused in literature (Gibb, 2001), a number of benefits have been cited. For example, addressing environmental, sustainability and waste (Pan and Arif, 2011; Jaillon et $a l, 2009$ ) or increasing project quality and improving onsite safety performance (Goodier and Gibb, 2005; Blismas et al, 2014). However, whilst acknowledging these benefits, AEC has also been criticised for its slow adoption of emerging technologies (Yang et al, 2007); the corollary of which has also been recognised as lagging behind other industries (Nadim and Goulding, 2011; Qasim, 2018). Conversely, this trend has started to change in recent years, particularly through increased awareness of OSC techniques and capabilities. That being said, this resurgence has yet to gain momentum in India, as the country has only recently begun considering using these practices (Arif et al., 2012).

Given the above developments in OSC and the need to embrace such initiatives in India, the premise of this paper was to evaluate the 'readiness' of the market - specifically, the degree to which Indian construction organisations could take advantage of OSC. In the context of 
'readiness', this was determined as 'a measure of the degree to which an organisation may be ready, prepared, or willing to obtain benefits which arise from OSC practices'. This proposition was developed based on the E-Readiness definition by (Goulding and Lou, 2013; Lou et al, 2019). The rationale for the development of this OSC readiness model was to investigate 'the major factors which influenced the decision-making process for adopting OSC over traditional methods'. The following section presents a discussion on the OSC variables, placing them in context with existing practices in India.

\section{Offsite Construction Readiness Variables}

\section{Complex interfacing systems}

The connections between various systems and individual products are often complex in OSC processes. Modern methods of construction require frequent communication and coordination between all the involved parties. However, the fragmented nature of the construction industry can sometimes make it harder to standardise designs for OSC (HCA, 2010). This can mean that modules or systems produced by different suppliers may not fit together properly, culminating in defects or lower quality (Rahman, 2013; Chan et al., 2016). Since modern methods of construction can differ from traditional methods, this can invite integration challenges (Innovate Offsite, 2010); or tolerance issues with interfaces between on-site and conventional systems when combined (BRE, 2001). Where for example, Pan et al., (2008) noted that interfacing problems were probably an inhibitor to the wider take-up of OFC. Design-related issues therefore need special attention (Darko et al., 2017).

\section{Duties and taxes}

Various excise and customs duties can be levied on OSC systems manufactured in the country or exported from foreign countries. These charges are often payable at various points during the construction process (Bendi, 2017). Whilst OSC is still relatively in its infancy in India, some advocates have suggested the use of tax incentives to promote uptake. For example, in the early 2000s, China introduced several market reforms including restructuring state-owned enterprises and setting up private initiatives; where tax incentives and duty-free imports of machinery were levied to encourage foreign investments (Zhao et al, 2006). Notwithstanding this, one of the main barriers to uptake is that of cost - compared to traditional methods (Mao et al., 2013; Rahman, 2013). These OSC costs, policies, inducements and tax implications therefore need to be fully understood from the outset (Arif and Egbu, 2010).

\section{Level of experience}

The Royal Institute of Chartered Surveyors (RICS) carries out a survey every year to record the skill shortages of construction workers. On average, over the survey's 45 history, only $40 \%$ of the employers used to report a lack of skilled workers. However, this shortage increased to $62 \%$ in 2017, which is significant (Wallace, 2017). Given that OSC predominantly requires a highly skilled workforce for both processes i.e. production of modules and parts in factories and accurate on-site assembly of modules (Jaillon and Poon, 2010; Zhang et al., 2018), this presents a further challenge to OSC uptake. This has been reported through a number of reports, where for example, Hong et al., (2018) highlighted the 
need for this to be addressed. Inexperienced staff is a major challenge to OSC (Pan et al, 2011); the corollary of which is that market demand is seen to be inextricably linked to service provision - as very few people are learning the skills required to deliver this provision (HCA, 2010).

\section{Risk-averse culture}

One of the main challenges often cited for OSC adoption is that of its pseudo 'negative' image, a precursor to early variants presented post World War I and World War II. Where (from a UK perspective), early attempts to produce prefabricated buildings were used to deliver housing shortages (predicated through the Housing Temporary Accommodation Act 1944). This provision had a design lifespan of 10 years; yet somewhat ironically, many of these prefabricated homes still exist today. Earlier initiatives in offsite started around 1837 where prefabricated homes were imported from the UK, USA and Singapore to Australia. The North American market later saw the development of the "Sears Modern Homes" circa 1908 (which used a ready to assemble approach or "kit house"), and post 1945 with the development of the "Lustron home". Thus, the perception of OSC (and inherent culture) is still linked to these early variants. Part of this culture is also linked to traditional ways of thinking, where new approaches are often seen as being 'risky', as the underpinning logic and business rationale often requires considerable consolidation time. Adopters often consider 'affordability' as part of this equation (Mtech, 2009), and the need to continue to make a profit (HCA, 2010; Pan et al, 2011), whilst not forgetting the rivalry between different manufacturers (Pan et al, 2008), and underpinning cynicism of OSC (Kamali and Hewage, 2017).

\section{Lead times}

The term "lead time" relate to an organisation's ability to align corporate resources with the execution process, cognisant of all internal and external interceding processes that affect the delivery and subsequent handover times. Delays are a major part of this, particularly between the initiation and execution of the process. Where Goodier and Gibb, (2005), observed that this was considered a major barrier to contractors; especially where the use of offsite could delay the commencement of the project on site (Killian et al., 2019). Factors affecting this issue often include: like lack of guidance in prefabrication; manufacturing capacity; level of experience; and complex interfacing between the modular systems (Mao et al., 2013; Zhai et $a l, 2014)$. In summary therefore, it is important to evaluate the potential impact of lead times in OSC, as this is seen as a significant barrier to designers, contractors and clients. That being said, a number of initiatives are already addressing this issue (Arif and Egbu, 2010; Goulding et al., 2015).

\section{Client resistance and scepticism}

In a similar context to the risk-averse culture highlighted above, industry reluctance to try new methods, or indeed to embrace change or be innovative, has directly affected OSC uptake (CRC, 2007; Innovate Offsite, 2010). This mind set can seriously hinder the innovation and adoption of off-site manufacturing, especially in new markets. This reluctance or scepticism is deep-rooted (BRE, 2001; Rahman, 2013; BURA, 2005), even including OSC's ability to be seen as a sound investment decision CRC (2007). However, things are 
changing in this respect, especially with the introduction of innovative vertically integrated offsite manufacturing (OSM) factory-driven solutions entering the market.

\section{Lack of guidance and support information}

Since the trend of OSC is relatively new, many countries are still in the process of realising the need to develop codes of practice and regulations related to OSC (Pan, Wong and Hui, 2011). Given this, the paucity of information and guidance on OSC methods has been seen as another barrier to its adoption (Goodier and Gibb, 2005; Kamar et al, 2009; CITB, 2017). This lack of guidance information on OSC was also acknowledged in India (Bendi, 2017).

\section{Transportation infrastructure}

The transportation infrastructure is often seen as a key contributor OSC uptake. This is especially so where the modules and parts required are geographically dispersed, or where sites have limited on-site space and/or access (BRE, 2007; Innovate Offsite, 2010; Rahman, 2013). This can affect the viability of OSC, especially in smaller sized projects (Jaillon and Poon, 2010). This challenge is further exacerbated where limited manufacturers exist (Dadzie et al., 2018; Darko and Chan, 2018). However, from a pollution perspective, OSC seems to be more environmental friendly than traditional methods (Krug, 2013).

\section{Manufacturing capacity}

The impact of manufacturing on OSC has been seen as a major advantage due to its impact on the overall quality and speed of delivery compared to traditional approaches. OSC is particularly suited to repetitive components, where high volume prevails with repeated processes (Innovate Offsite, 2010). However, the initial set-up costs can be high and it can be difficult to maintain consistent demand throughput to meet assembly line production methods/requirements (Chiang et al., 2006; DesignBuilding, 2019). Manufacturing capacity is therefore a key component, as the viability of OSC is related to an organisation's planning and utilisation of these manufacturing facilities (Goodier and Gibb, 2005; Mao et al., 2016; Jiang et al., 2018).

\section{Local availability}

Local availability includes the proximity of goods and services to the intended OSC marketplace. Such that it is more beneficial to provide pockets of supply to local service providers, than wider non-cognate distribution centres. This also impinges on the carbon footprint and wider environmental impact. Limited local availability can therefore imping on the decision to adopt OSC (Innovate Offsite, 2010; Rahman, 2013; Bendi, 2017).

\section{Codes/standards available}

Codes of practice in OSC tend to embrace technical guidelines and specifications for designers, operators and installers. As OSC is still relatively recent, in some areas there is a lack of 'approved' design standards or codes of practice (Pan et al, 2011; Goodier and Gibb, 2005; Kamar et al, 2009; CITB, 2017). Moreover, these challenges are often country-specific (Nadim and Goulding, 2011); resulting in fewer standards and codes (HCA, 2010; Rahman, 2013). 


\section{Environmental impact during construction}

AEC development has been seen to be a significant contributor to global $\mathrm{CO}_{2}$ emissions, where approximately $25 \%$ of emissions are attributable to energy use in buildings (IPCC, 2007). However, several studies have highlighted that OSC can help reduce these emissions, whilst also contributing to reduced waste outputs and fewer resource requirements (WRAP, 2008; Monahan and Powell, 2011). One description of sustainable construction has been defined as "the creation and responsible management of a healthy built environment based on resource efficient and ecological principles" (Jaillon and Poon, 2010). Thus, the environmental impact of construction activity needs to be carefully controlled, from landfill (Jaillon et al, 2009; Gong et al., 2019), through to transportation (Krug, 2013).

\section{Capital cost}

Capital costs tend to include the strategies and financial requirements in terms of capital investment needed to service its business. From an OSC perspective, these are important factors to consider (Rahman, 2013), as higher costs are often seen as a significant barriers in the selection process. Whilst opinion is still unfolding on the true costs of OSC in comparison with conventional approaches (as comparison rarely compare like with like), some have indicated that offsite can be more expensive than traditional methods in some circumstances (Goodier and Gibb, 2005). This is due in part to the higher start-up costs needed to develop appropriate prefabrication facilities and machinery needed to produce modular components (Chiang et al., 2006; BRE, 2007). OSC also tends to require higher up-front costs for the purchase of materials at the beginning of a project (Mtech, 2009). Thus, perceived higher initial capital outlay costs can be seen as barrier to OSC uptake (Pan et al., (2007); Pan and Sidwell, 2011). That being said, once this initial investment has been absorbed into organisational business models, several opportunities can be leveraged, especially though economies of scale (Arif et al., 2012).

\section{Cost certainty}

The delivery of cost certainty places particular emphasis on the planning, monitoring and controlling of all project-related costs. This is seen as a fundamental prerequisite for both contractors and clients (Xiao and Proverbs, 2003), where fixity and reliability is important (Antoine et al, 2018). However, OSC can be particularly beneficial in achieving cost certainty and (Lusby-Taylor et al., 2004). That being said, cost surety requires stability, with minimal changes (Pan et al. 2011; Rahman, 2013) so that variances are minimised.

\section{Time certainty}

Time certainty represents the reliability and certainty of finishing projects within the promised timescale. Time certainty is consistently one of the highest priorities for construction clients (Pérez et al, 2010; Hartmann and Hietbrink, 2013), especially as project delays and cost overruns eventually lead to increased costs and client dissatisfaction. Clients expect projects to be completed within the promised timescale and budget. This also has an impact on the profitability of companies, along with reduced product confidence (Xiao and Proverbs, 2003). From an OSC perspective, time certainty is generally improved in comparison to traditional approaches, as it is normal to 'fix' design decisions at a very early stage (Pan et al, 2008). The downside of this early design fixity is the OSC's relative 
inability to accommodate late design changes, as more often than not, production schedules will have already commenced (BRE, 2007; Jaillon and Poon, 2010).

\section{Minimising on-site duration}

Similar to time certainty, the use of OSC can often reduce the amount of time spent on site due to the pre-manufacturing process. This is particularly advantages during inclement weather, where traditional approaches are often hindered. Clients require projects to be delivered in accordance with the corresponding brief and standards, cognisant of time constraints and standards of quality expected (Martin et al., 2006; Aziz et al, 2017). Studies comparing successful completion times and costs between traditional and OSC methods highlight that only $34 \%$ of traditional construction projects were delivered on time, and $61 \%$ to the agreed contract sum UKIPR, $(2012,2015)$; where in comparison, $97 \%$ of OSC projects were completed on time and within budget. Thus, it is important to minimise the on-site duration to minimise time and cost variables in order to achieve project deliverables (Blismas and Wakefield, 2009; Pan et al, 2008; Mostafavi et al., 2012).

\section{Speed of delivery}

From a delivery perspective, Lusby-Taylor et al., (2004) highlighted that the speed construction of OSC was a major advantage. Where for example Krug, (2013), noted that OSC methods were up to $60 \%$ faster than conventional construction methods. This is therefore seen as a major driver for the adoption of OSC (Arif et al., 2012; Ajayi et al., 2016). Speed of delivery is therefore seen as a main factors for OSC deployment (Blismas and Wakefield, 2009; Kamali and Hewage, 2017).

\section{Conclusion}

The above factors derived from literature helped identify the key variables that potentially impinged or impacted the OSC decision making process. Given the need to contextualise these factors into sentient units of analysis for evaluation within the Indian OSC market, the next stage in this process was to develop a research methodological approach which captured stakeholders' needs in order to embed the rubrics of these into an OSC readiness model.

\section{Research Methodology}

After the design of the questionnaire, it was initially evaluated through piloting prior to its final distribution. The initial draft version of the questionnaire was sent for comments to eight respondents in both academia and industry. The research topic and the rationale of research were explained to them in detail. Feedback from these experts resulted in more clarity in some of the variables descriptions and helped in removing a minor technical error. These issues were addressed in the revised questionnaire before final distribution to a larger group. The feedback and comments obtained from the pilot survey thus helped in refining the overall design and structure of the questionnaire. The questionnaire focused on the views of Architectural, Engineering and Construction (AEC) professionals in regard to OSC, current practices and the delivery of Off-Site Construction projects in India. The research was centred on developing a readiness model for utilising OSC techniques in construction organisations in India. Therefore, organisations applying OSC were more familiar with both the philosophy and the principals involved. Hence, the best samples in making this inquiry 
were those of construction organisations who have adopted OSC techniques in their projects. However, being that the total number of Indian construction organisations implementing OffSite Construction is unknown, a purposive non-probability sampling technique was adopted (Bryman and Bell, 2007). After the survey data collection, five professionals were interviewed (for further prioritisation of variables), each with more than 15 years of experience in the Indian construction industry and OSC.

This research aimed to develop an OSC readiness model for Indian construction organisations. In order to achieve that aim, this research attempted to understand reality through the evidence and experiences of the current OSC practitioners in Indian construction; hence, dealing with the objective data. In parallel, this research also investigated the key factors which encourage or hinder the adoption of OSC practices in India. For this, the author endeavoured to observe the current practices as well as the perceptions and consequent actions of other social factors, such as awareness and people's perception. Hence, the ontological stand of current research lies more towards the subjectivism.

A total of 204 responses were received from professionals using the web-based questionnaire survey. The questionnaire helped determine different variables which impact most companies in OSC. The data was then analysed using SPSS software. Initially, the main issue was the large number of variables highlighted by the questionnaire and it was critical to identify any possible correlation between these variables. In case if there was any relationship between the variables, factor analysis was used to highlight it. The main purpose of factor analysis is to investigate the potential relationship between variables, in order to group them into factors. According to Field (2005), factor analysis reveals the measuring aspects of various variables. In this research, 26 variables were identified from the literature review. After factor analysis, the number of variables was reduced to 17 and then these variables were categorised into four (4) groups and the maximum likelihood method was adopted with the varimax rotation technique. KMO and Barlett test was performed after the factor analysis to know the measure of sampling adequacy and the reliability of the factor analysis. The output of this test contains the Kaiser-Meyer-Olkin measure of sampling adequacy and Barlett's test of sphericity.

Figure 1 specifies the four major steps in the methodology of this research paper. The first one is the evaluation of different variables compiled from the literature review. Survey results were then analysed using factor analysis which resulted in the formation of four major factors. Finally, the semi-structured interviews prioritised these factors in a brainstorming session.
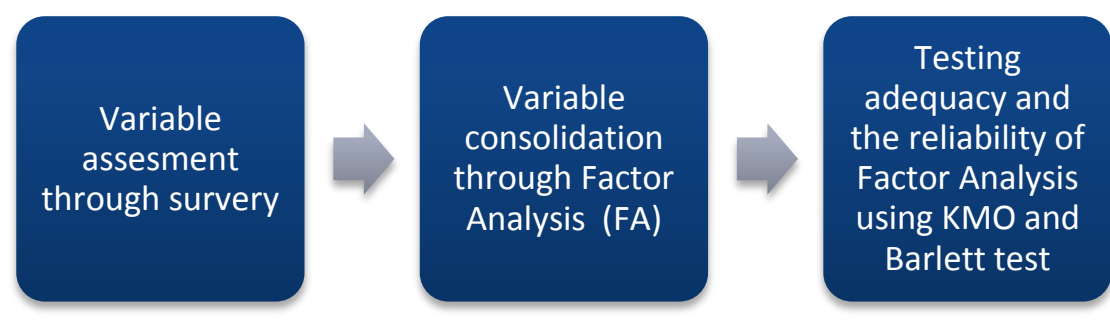

Prioritisation of factors through

semi-structured

Interviews

Figure 1 Research Methodology 


\section{Results and Analysis}

The majority of the participants were Engineers (55 in number), while architects were the second highest number (52). The cumulative of architects and engineers among the data set was 52.5\%; this means that 107 respondents belong to A\& E domains of the construction industry. The survey only attracted 11 policy makers, who represented $5.4 \%$ of the total respondents. The participants were from a variety of age groups, education levels and years of work experience as shown in Table 1.

\section{Factor Analysis Output 5}

The Scree plot is a graph of the eigenvalues which is plotted against the ordinal numbers of the factors extracted (Kinner and Gray 2010). The graph is useful to determine the remaining factors. The point of interest is where the curve begins to flatten out. From the following graph, it is understood that the curve starts to flatten between the components 5 and 6 . Hence only four factors will be used for relationship analysis.

\section{Factor Analysis Output 7}

The main purpose of factor analysis was to investigate the potential relationship between variables, in order to group them into factors. Rotated Component Matrix shows the factor loading for individual variables with respect to the factor (Tang, L., \& Shen, Q, 2013). The Rotated Component Matrix provided in Error! Reference source not found. has helped in grouping the 17 variables into four groups. This grouping is performed based on the loadings for all 17 variables exceeding $0.5(\mathrm{p}<0.01)$. Hence, each group was separated based on the loadings of more than 0.5 .

It can be seen it Error! Reference source not found. that the complex interfacing between systems, duties and taxes, no experience of its use, risk-averse culture, longer lead times, client resistance and scepticism and the lack of guidance and information are rewarded under Factor -1 (Operational Challenges). Similarly, the lack of transportation infrastructure, the lack of manufacturing capacity, the lack of local availability and the few codes/standards being available, the negative image and higher capital cost are loaded on Factor-2 (Strategy). Other factors, such as ensuring cost certainty and ensuring time certainty, minimising the onsite duration and speed delivery, are rewarded under Factor-3 (Planning Certainty) and Factor-4 (Operational Impact), respectively. It can be concluded that there are four groups for the variables that have an impact on OSC readiness.

Table 1 Respondent's Profession

\begin{tabular}{llll}
\multirow{4}{*}{ Valid } & Profession & Frequency & Percent \% \\
\cline { 2 - 4 } & Architect & 52 & 25.5 \\
& Engineer & 55 & 27.0 \\
\hline Developer & 32 & 15.7 \\
Manufacturer / supplier & 16 & 7.8 \\
Policy maker & 11 & 5.4 \\
Contractor & 38 & 18.6
\end{tabular}


100.0

Table 2 Current Position in Organisation

\begin{tabular}{llll}
\multirow{2}{*}{ Valid } & Director & Frequency & Percent \% \\
\cline { 2 - 3 } & Senior Manager & 18 & 8.8 \\
\hline Middle level & 64 & 31.4 \\
Technical staff & 109 & 53.4 \\
Total & 13 & 6.4 \\
\hline
\end{tabular}

Table 3 Work Experience

\begin{tabular}{l|lll} 
& & Frequency & Percent $\%$ \\
Valid & < years & 91 & 44.6 \\
5 to 10 years & 56 & 27.5 \\
10 to 15 years & 40 & 19.6 \\
$>15$ years & 17 & 8.3 \\
Total & 204 & 100.0
\end{tabular}

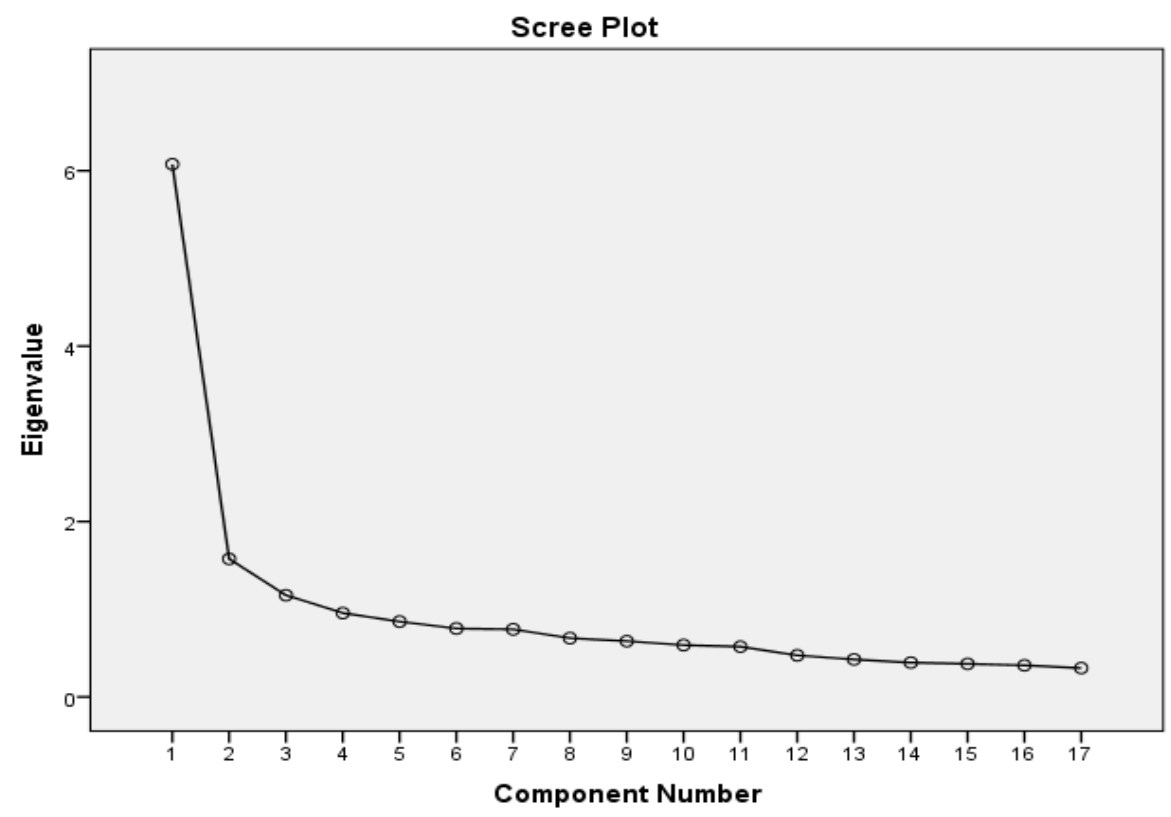

Figure 2 Scree Plot 


\begin{tabular}{|c|c|c|c|c|}
\hline \multirow[b]{3}{*}{$\begin{array}{l}\text { Complex interfacing between } \\
\text { systems }\end{array}$} & \multicolumn{4}{|c|}{ Component } \\
\hline & 1 & 2 & 3 & 4 \\
\hline & .712 & .265 & .024 & .033 \\
\hline Duties and Taxes & .704 & .145 & -.034 & -.156 \\
\hline No experience of its use & $\overline{.684}$ & .222 & .046 & -.067 \\
\hline Risk averse culture &.$\overline{.625}$ & .208 & -.265 & -.113 \\
\hline Longer lead times & .621 & .152 & -.187 & .061 \\
\hline Client resistance \& scepticism & $\overline{.567}$ & .360 & -.112 & -.208 \\
\hline Lack of guidance and information & .519 & .466 & -.113 & -.038 \\
\hline Lack of transportation infrastructure & .124 & .804 & -.009 & -.036 \\
\hline Lack of manufacturing capacity & .192 &.$\overline{670}$ & -.246 & -.025 \\
\hline Not locally available & .368 & $\overline{.586}$ & -.049 & -.023 \\
\hline Few codes/standards available & .464 & .563 & .063 & -.109 \\
\hline Negative image & .435 & $\underline{.551}$ & -.031 & -.354 \\
\hline Higher capital cost & .458 & $\overline{.548}$ & -.034 & -.108 \\
\hline $\begin{array}{l}\text { Ensuring cost certainty / Reliability } \\
\text { in cost }\end{array}$ & -.097 & $\overline{.006}$ & .807 & -.118 \\
\hline Ensuring time certainty & -.070 & -.214 & .717 & .293 \\
\hline Minimizing on-site duration & -.047 & -.130 & $\overline{-.112}$ & $\underline{.826}$ \\
\hline Speed delivery & -.137 & .011 & .437 & $\overline{.716}$ \\
\hline
\end{tabular}

\section{Model Development}

The model containing four factors was developed at this stage after performing factor analysis, which was further improved by performing reliability analysis, KMO and Barlett's test, Communalities test and Total Variance explained. Once the factors and their variables were finalised, the next step was to refine the model and understand the model by focusing on the importance of these factors. To understand this further, 5 experts in the offsite construction domain were interviewed with each with more than 15 years of experience in the Indian construction industry. Each of them also possessed more than five years of experience in working with OSC methods.

During the semi-structured interviews with the experts, the scope of each sub-factor was explained to all the participants. Two participants expressed their disagreement with the scope of the sub-factor 'Duties and taxes'. They restructured the scope, and the modifications were made accordingly. The content of maturity levels was addressed in the third question and they were asked about the adequacy of the number of levels and their appropriateness for assessing the OSC readiness of construction organisations in India. Participants were also encouraged to suggest any alternative numberings, with appropriate reasoning. All the participants agreed with the number of maturity levels in the framework. However, one participant expressed that the description of maturity levels needed more specification that 
was addressed as well which was addressed as well. After merging, 17 variables were grouped as shown in Figure 3.

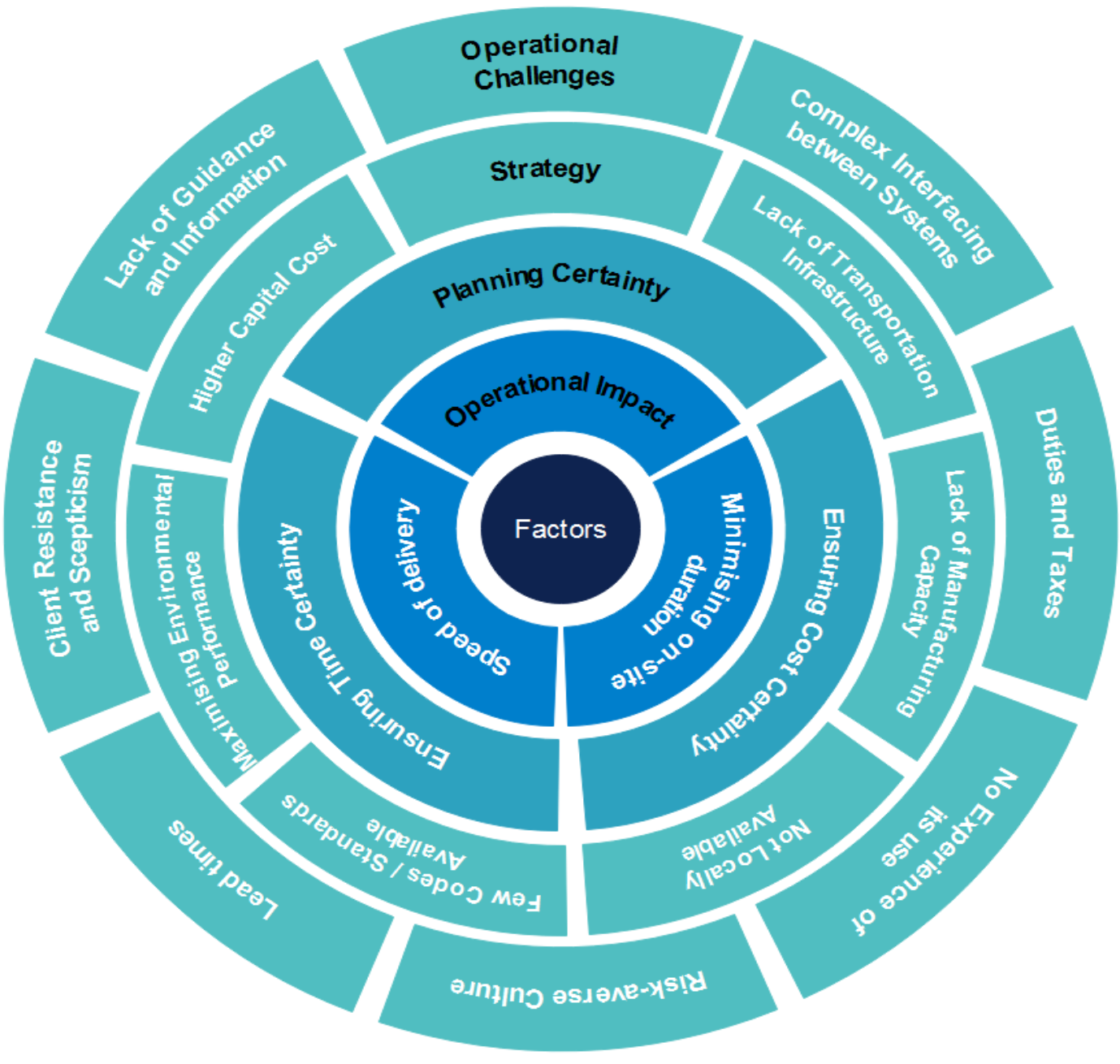

Figure 3 Results of Factor Analysis.

After the factor analysis, the second output from the analysis is a table of descriptive statistics for all variables under investigation. The following table presents the mean, standard deviation and the number of respondents $(\mathrm{N})$ who participated in the survey. According to this analysis, the highest mean is 3.91, and thus the most significant variable is "minimising on-site duration". In addition, all the variables scored the mean value higher than 1 , which indicate that all the extracted variables have impact on the practice of Off-Site Construction in India.

Table 4 Descriptive Statistics of variables under investigation

\begin{tabular}{lc|c|c|} 
Variable & N & Mean & Std. Deviation \\
Ensuring cost certainty / Reliability in & 204 & 3.18 & .755 \\
cost & & & \\
Ensuring time certainty & 204 & 3.44 & .843 \\
Minimizing on-site duration & 204 & 3.91 & .883 \\
Complex interfacing between systems & 204 & 2.43 & 1.096 \\
Duties and Taxes & 204 & 2.48 & 1.103 \\
No experience of its use & 204 & 2.48 & 1.071
\end{tabular}




\begin{tabular}{|l|c|c|c|}
\hline Risk averse culture & 204 & 2.55 & 1.023 \\
\hline Longer lead times & 204 & 2.84 & .977 \\
\hline Client resistance \& scepticism & 204 & 2.40 & 1.155 \\
\hline Lack of guidance and information & 204 & 2.52 & 1.292 \\
Lack of transportation infrastructure & 204 & 2.43 & 1.127 \\
Lack of manufacturing capacity & 204 & 2.47 & 1.129 \\
Not locally available & 204 & 2.43 & 1.036 \\
Few codes/standards available & 204 & 2.31 & 1.077 \\
Negative image & 204 & 2.40 & .985 \\
Higher capital cost & 204 & 2.48 & 1.048 \\
Speed delivery & 204 & 3.74 & .859
\end{tabular}

\section{Discussion}

The literature review and data analysis from the questionnaires helped in identifying the key factors that have a significant influence on the Off-Site Construction (OSC) readiness of the construction organisations. Further, the factor analysis enabled the author to group the subfactors under the relevant key factors. In the next stage, a conceptual model was developed to assess the OSC readiness of construction organisations. The process was started by listing the key factors (F1: Operational challenges, F2: Strategy, F3: Certainty planning and F4: Operational efficiency) and the respective components of the key factors, along with the definitions. Afterwards, factor analysis was conducted to identify and group the most prioritised factors in the case of India. This had provided a list of 17 variables in four groups. A conceptual readiness framework was constructed based on these variables which were further refined by semi-structured interviews.

The first factor is operational challenges which have the seven operational or ground-level issues. The complex interfacing problem between prefabricated modules is a global concern due to the fragmentation in the construction sector and the reluctance to share the best practices among them for competition purposes. If different off-site interfaces do not lock properly, their strength will be compromised. This can then result in trust issues and triggering the client resistance/scepticism and time/cost certainty issues. The communication has to be to be enhanced and new platforms and forums can encourage this problem. Since OSC is relatively new, the capital costs are higher in the beginning and it needs to be addressed using duties and taxes incentives and duty free imports initially. The level of experience is among the topmost imperative variables identified and is also linked to the recent entry of OSC in the Indian construction sector ending up in a shortage of skilled and knowledgeable workers. They lack skills in both processes i.e. production of components and modules in the factories and the assembly of these modules on the site. Level of experience is also linked with the size of an industry in the country, if the market is really small; it means that very few people will be using this method of construction implying that fewer people will be able to learn these skills. When any industry expands, there are more opportunities for new entrants and knowledge is transferred from top to bottom. On the contrary, if the size of industry is small and it is relatively new, it not only faces lack of adequate information and guidance but also the shortage of skilled workforce. Literature review suggested that variables like lack of guidance in OSC, level of experience, manufacturing capacity and complex interfacing problems can lead to longer lead times eventually. This means another 
barrier in the adoption of OSC and it will further enhance the risk-averse culture, reluctance and scepticism about the modern methods of construction. All these variables are interlinked closely and impact each other like a chain reaction.

The second factor is on a strategical level including transportation, codes of practice and manufacturing capacity. The issues at the strategic level severally impact the likelihood to use the OSC methods. The transportation infrastructure has to be of adequate standard for OSC since the modules developed off-site are usually large and of complex shapes. If the ground infrastructure cannot support it, or the distances (between factory and site) are very long, it will simply put-off the contractors and clients from using OSC. Transportation of modules adds up to the environmental impact of construction as well. Construction is already one of the least efficient sectors and any unnecessary waste or increase of emissions has to be minimised. This strategic factor also includes manufacturing capacity and local availability of the modules and raw material respectively. When the OSC sector is relatively new in a country, its manufacturing capacity is naturally low. It will increase over the time or by an external drive whether it is from the government or clients. Another reason for the lack of manufacturing capacity can be the higher capital costs attached with the OSC and it is also one of the biggest barriers in its adoption worldwide. Being the manufacturing powerhouse, China had addressed this barrier by achieving the economies of scale. While this industry has recently entered the construction sector and is still passing the early stages, there will be natural lack of guidance and information about it, which is another important variable affecting the OSC in India. If there is no government initiative to fix it, local building councils can develop their own codes of practice with time.

Third factor is planning certainty which covers both the cost and time certainty variables in the construction. During project delivery, cost certainty is an important point where an agency obtains a reliable and fixed cost of the project and same is the case with time certainty variable. OSC has a completely different style of work compared to traditional construction works. In OSC, the designs and plans are decided and frozen at the beginning of the project to give enough time for prefabrication of materials and it manages the time/cost certainty issue to some extent. However, this also makes OSC less flexible and also unsuitable for late design changes which can be another barrier in its adoption.

Fourth factor is the operational impact which looks at minimising on-site duration and speed of delivery. This has been marked as the most important variable in the uptake of OSC in India. Majority projects are delayed every year due to poor planning and scope creeps resulting in customer dissatisfaction. Literature review showed $97 \%$ projects were delivered within time and cost using OSC as compared to 34-61\% using traditional methods of construction. This means that OSC performs very well in this criterion which was ranked highest during the analysis.

\section{Conclusion}

The aim of this study was to create a model to understand the readiness and eventually facilitate the off-site construction methods in the Indian construction sector. However, more analysis needs to be performed to assess the applicability of this model in other countries and 
sectors. The variable most important for an organisation regarding the OSC readiness was minimising the on-site duration of the work. Here on-site duration means the period of time between the date of construction contract start on the site and the date of the final completion. The second most important variable was ensuring the cost and time certainty. Time and cost are both tied to each other and any issue with the planning, design changes or disruptions will upset both of these dimensions. The third important variable was the issue of transportation which includes the shipping of large off-site produced components and the issue of emissions linked to it. If the construction site is at a far-flung area or not accessible for large vehicles, OSC may simply not be feasible/possible. The least important variable was the availability of standards when compared to other, more critical factors. The results of this research have several implications for the Indian construction companies.

This research work has made some significant and original contributions, especially on OSC readiness. Previous research has not endeavoured to bring these factors together into a cohesive model for the Indian offsite construction sector. The findings of this research are significant, however, there is a major limitation that the data collected and analysed was only from India. Therefore, the model is not generalizable unless further data is collected from other countries, suitably examined and eventually implanted into this model. This model can be taken as a starting point by future researchers and contextualise it in their own countries. 


\section{References}

Ajayi, Saheed O., Oyedele, Lukumon O., Akinade, Olugbenga O., Bilal, Muhammad Owolabi, Hakeem A., Alaka, Hafiz A. and Kadiri, Kabir O. (2016) 'Reducing waste to landfill: A need for cultural change in the UK construction industry', Journal of Building Engineering. doi: 10.1016/j.jobe.2015.12.007.

Antoine, A. L. C., Alleman, D. and Molenaar, K. R. (2018) 'Examination of Project Duration, Project Intensity, and Timing of Cost Certainty in Highway Project Delivery Methods', Journal of Management in Engineering, 35(1), p. 04018049. doi: 10.1061/(asce)me.1943-5479.0000661.

Arif, M., Bendi, D., Toma-Sabbagh, T. and Sutrisna, M., 2012. Construction waste management in India: an exploratory study. Construction innovation, 12(2), pp.133155.

Arif, M., Bendi, D., Sawhney, A. and Iyer, K.C., 2012. State of offsite construction in IndiaDrivers and barriers. In Journal of Physics: Conference Series (Vol. 364, No. 1, p. 012109). IOP Publishing.

Arif, M. and Egbu, C. (2010) 'Making a case for offsite construction in China', Engineering, Construction and Architectural Management, 17(6), pp. 536-548. doi: 10.1108/09699981011090170.

Aziz, Z., Qasim, R. M. and Wajdi, S. (2017) 'Improving productivity of road surfacing operations using value stream mapping and discrete event simulation', Construction Innovation, 29(1), pp. 1-6. doi: 10.1108/EL-01-2014-0022.

Bendi, D. (2017) Developing an offsite readiness framework for Indian construction organisations, PhD Thesis.

Blismas, N., Gibb, A. and Pasquire, C. (2014) 'Assessing Project Suitability for Off-site Production', Construction Economics and Building. doi: 10.5130/ajceb.v5i1.2938.

Blismas, N. and Wakefield, R. (2009) 'Drivers, constraints and the future of offsite manufacture in Australia', Construction Innovation, 9(1), pp. 72-83. doi: 10.1108/14714170910931552.

British Urban Regeneration Association (BURA) (2005) odern methods of construction: Evolution or revolution? London.

Building Research Establishment (BRE) (2001) Current practice and potential uses of prefabrication. Watford, U.K.

Building Research Establishment (BRE) (2007) Modern methods of construction (MMC) in housing: Parts I-IV. Watford, U.K.

Chan, A.P., Darko, A., Ameyaw, E.E. and Owusu-Manu, D.G., 2016. Barriers affecting the adoption of green building technologies. Journal of Management in Engineering, 33(3), p.04016057.Chiang, Y. H., Hon-Wan Chan, E. and Ka-Leung Lok, L. (2006) 'Prefabrication and barriers to entry-a case study of public housing and institutional buildings in Hong Kong', Habitat International. doi: 10.1016/j.habitatint.2004.12.004.

CITB (2017) Faster, Smarter, More Efficient: Building Skills for Offsite Construction. Available

at: https://www.citb.co.uk/documents/research/offsite_construction/offsite_construction _full_report_20170410.pdf (Accessed: 7 May 2019).

Cooperative Research Centre for Construction Innovation (CRC) (2007) Offsite manufacture in Australia: Final report. Brisbane, Australia.

Dadzie, J., Runeson, G., Ding, G. and Bondinuba, F., 2018. Barriers to Adoption of Sustainable Technologies for Energy-Efficient Building Upgrade-Semi-Structured Interviews. Buildings, 8(4), p.57.

Darko, A., Chan, A.P., Owusu-Manu, D.G. and Ameyaw, E.E., 2017. Drivers for implementing green building technologies: An international survey of experts. 
Journal of cleaner production, 145, pp.386-394.

Darko, A. and Chan, A. P. C. (2018) 'Strategies to promote green building technologies adoption in developing countries: The case of Ghana', Building and Environment. doi: 10.1016/j.buildenv.2017.12.022.

DesignBuilding (2019) Off-site construction - Designing Buildings Wiki. Available at: https://www.designingbuildings.co.uk/wiki/Off-site_construction (Accessed: 7 May 2019).

Gibb, A. G. F. (2001) 'Standardization and pre-assembly- distinguishing myth from reality using case study research', Construction Management and Economics. doi: 10.1080/01446190010020435.

Gong, P., Teng, Y., Li, X. and Luo, L., 2019. Modeling constraints for the on-site assembly process of prefabrication housing production: a social network analysis. Sustainability, 11(5), p.1387.

Goodier and Gibb (2005) 'Barriers and Opportunities for Offsite in the UK', Abdul Samed Kazi,ed. Systematic Innovation in the Management of Project and Processes, 11th Joint CIB International Symposium, 13-16 June 2005, pp. 148-158.

Goulding, J.S., and Arif, M., (2013), Research Road Map Report: Offsite Production and Manufacturing, Publication 372, International Council for Research and Innovation in Building and Construction, ISBN 978-90-6363-076-8 https://site.cibworld.nl/dl/publications/pub_372.pdf

Goulding, J.S, and Lou, E.C.W, (2013), E-Readiness in Construction: An Incongruous Paradigm of Variables, Journal of Architectural Engineering and Design Management, Vol. 9, Iss. 2., pp. 265-280, 2013, DOI: $10.1080 / 17452007.2013 .775099$

Goulding, J.S, and Pour Rahiminan, F., (Eds.), (2019), Offsite Production and Manufacturing for Innovative Construction: People, Process and Technology, Taylor and Francis, UK, ISBN: 978-1-138-55068-1

Goulding, J.S., Pour Rahimian, F., Arif, M. and Sharp, M.D., 2015. New offsite production and business models in construction: priorities for the future research agenda. Architectural Engineering and Design Management, 11(3), pp.163-184.

Gupta, R., Jambunatahan, S. and Netzer, T, (2009) Building India: Accelerating Infrastructure Projects. Mumbai, India. Available at: https://www.mckinsey.com/ /media/mckinsey/industries/travel transport and logistics/our insights/transforming indias logistics infrastructure/building_india transforming_the_nations_logistics_infrastructure.ashx (Accessed: 8 May 2019).

Hartmann, A. and Hietbrink, M. (2013) 'An exploratory study on the relationship between stakeholder expectations, experiences and satisfaction in road maintenance', Construction Management and Economics. doi: 10.1080/01446193.2013.768772.

Homes, and C. A. (HCA) (2010) Designed for manufacture: The challenge to build a quality home for $£ 60 \mathrm{k}$, lessons learnt. London.

Hong, J., Shen, G.Q., Li, Z., Zhang, B. and Zhang, W., 2018. Barriers to promoting prefabricated construction in China: A cost-benefit analysis. Journal of cleaner production, 172, pp.649-660.

Innovate Offsite (2010) 'Aguide to offsite and howit is being made to work today', Innovate Offsite Magazine, Mtech Consult.

Intergovernmental Panel on Climate Change - IPCC (2007) Climate Change 2007: Mitigation. Contribution of working group III to the fourth assessment report of the Intergovernmental Panel on Climate Change, Intergovernmental Panel on Climate Change.

Jaillon, L. and Poon, C. S. (2010) 'Design issues of using prefabrication in hong kong building construction', Construction Management and Economics. doi: 10.1080/01446193.2010.498481. 
Jaillon, L., Poon, C. S. and Chiang, Y. H. (2009) 'Quantifying the waste reduction potential of using prefabrication in building construction in Hong Kong', Waste Management. Elsevier Ltd, 29(1), pp. 309-320. doi: 10.1016/j.wasman.2008.02.015.

Jiang, R., Mao, C., Hou, L., Wu, C. and Tan, J., 2018. A SWOT analysis for promoting offsite construction under the backdrop of China's new urbanisation. Journal of cleaner production, 173, pp.225-234.

Kamali, M. and Hewage, K. (2017) 'Development of performance criteria for sustainability evaluation of modular versus conventional construction methods', Journal of Cleaner Production. doi: 10.1016/j.jclepro.2016.10.108.

Kamar, K. A. M., Alshawi, M. and Hamid, Z. A. (2009) 'Barriers To Industrialized Building System (IBS): The Case of Malaysia', in Built and Human Environment 9th International Postgraduate Research Confrence (IPGCR 2009).

Killian, P., Arif, M., Wood, G. and Kaushik, A., (2016). Offsite Construction in the UK Housing Sector: Barriers and Challenges. Modular and Offsite Construction (MOC) Summit Proceedings, 1(1).

KPMG (2016) Urban Real Estatae: Promising Opportunities, Available from: https://assets.kpmg/content/dam/kpmg/in/pdf/2016/08/Urban_Indian_real_estate.pdf (Accessed 4 July 2019).

Krug, D. (2013) OFFSITE CONSTRUCTION: Sustainability Characteristics. Available at: https://www.buildoffsite.com/content/uploads/2015/03/BoS_offsiteconstruction_130 7091.pdf (Accessed: 8 July 2019).

Lou, E.C.W, Lee, A., and Goulding, J.S., (2019), E-Readiness in Construction (ERiC): SelfAssessment Framework for UK Small and Medium Enterprise Building Services Providers, Architectural Engineering and Design Management, https://doi.org/10.1080/17452007.2019.1617669

Lusby-Taylor, P., Morrison, S., Ainger, C. and Ogden, R., 2004. Design and Modern Methods of Construction. The Commission for Architecture and the Built Environment (CABE), London.

Maniar, H. (2010) 'Risk Analysis of Infrastructure Projects : A Case Study on Build-OperateTransfer Projects in India', Journal of Financial Risk Management.

Mao, C., Shen, Q., Pan, W. and Ye, K., 2013. Major barriers to off-site construction: the developer's perspective in China. Journal of Management in Engineering, 31(3), p.04014043.

Mao, C., Xie, F., Hou, L., Wu, P., Wang, J. and Wang, X., 2016. Cost analysis for sustainable off-site construction based on a multiple-case study in China. Habitat International, 57, pp.215-222.

Martin, J., Burrows, T.K. and Pegg, I., 2006, October. Predicting construction duration of building projects. In XXIII Congreso FIG, Octubre de 2006.

McGraw-Hill Construction (2011), 'Prefabrication and Modularization: Increasing Productivity in the Construction Industry', Smart Market Report series, McGrawHill Construction, Bedford, MA, USA.

Monahan, J. and Powell, J. C. (2011) 'An embodied carbon and energy analysis of modern methods of construction in housing: A case study using a lifecycle assessment framework', Energy and Buildings. Elsevier B.V., 43(1), pp. 179-188. doi: 10.1016/j.enbuild.2010.09.005.

Mostafavi, A., Valentin, V., Abraham, D.M. and Louis, J., 2012. Assessment of the productivity of nighttime asphalt paving operations. Journal of Construction Engineering and Management, 138(12), pp.1421-1432.

Mtech Consult Limited (Mtech) (2009) Offsite and MMC in affordable housing. Shrewsbury, U.K.

Nadim, W. and Goulding, J. S. (2011) 'Offsite production: A model for building down barriers A European construction industry perspective', Engineering, Construction 
and Architectural Management. doi: 10.1108/09699981111098702.

NITI Aayog (2018) Annual Report 2017-18. New Delhi, India. Available at: https://niti.gov.in/writereaddata/files/document_publication/Annual-ReportEnglish.pdf (Accessed: 8 May 2019).

Pan, Y, Wong, F. K. W. and Hui, E. C. M. (2011) 'Application of industrialized housing system in China: A Chongqing study', Modeling risk management in sustainable construction, computational risk management, (Springer-Verlag, Berlin), p. Springer-Verlag, Berlin.

Pan, W. and Arif, M. (2011) 'Manufactured construction:Revisiting the construction manufacturing relations', in Proceedings of the 27Th Annual Conference, pp. 105114.

Pan, W., Gibb, A. F. and Dainty, A. R. J. (2007) 'Perspective of UK housebuilders on the use of offsite modern methods of construction', Construction Management and Economics. doi: 10.1080/01446190600827058.

Pan, W., Gibb, A. G. . and Dainty, A. R. . (2008) 'Leading UK housebuilders ' utilisation of offsite modern methods of construction', Building Research \& Information, 36(1). Available at: https://dspace.lboro.ac.uk/dspace-jspui/bitstream/2134/6181/1/Pan.pdf.

Pérez, P. B., González-Cruz, M. and Pastor-Ferrando, J. P. (2010) 'Analysis of construction projects by means of value curves', International Journal of Project Management. doi: 10.1016/j.ijproman.2009.11.003.

Qasim, R. M. (2018) Improving highways construction processes using computer-based simulation techniques. University of Salford. Available at: http://usir.salford.ac.uk/id/eprint/49496/.

Rahman, M. M. (2013) 'Barriers of Implementing Modern Methods of Construction', Journal of Management in Engineering, 30(1), pp. 69-77. doi: 10.1061/(asce)me.1943-5479.0000173.

Shrivastava, S. and Chini, A. (2011) 'Construction Materials and C\&D Waste in India.', in Lifecycle Design of Buildings, Systems and Materials.

UKIPR (2012) Based on the UK Construction Industry Key Performance Indicators Contents. Available https://www.glenigan.com/sites/default/files/UK_Industry_Performance_Report_20 16_LR.pdf (Accessed: 7 May 2019).

UKIPR (2015) 'UK Industry Performance Report: Based on the UK Construction Industry Key Performance Indicators'. Available at: https://www.glenigan.com/sites/default/files/UK_Industry_Performance_Report_20 15_883.pdf.

Umar, U.A., Shafiq, N., Malakahmad, A., Nuruddin, M.F. and Khamidi, M.F., 2017. A review on adoption of novel techniques in construction waste management and policy. Journal of Material Cycles and Waste Management, 19(4), pp.1361-1373.

Wallace, T. (2017) 'Skills shortage tightens around UK construction sector', The Telegraph, 16 November, pp. 1-3. Available at: http://www.telegraph.co.uk/business/2017/11/16/skills-shortage-tightens-around-ukconstruction-sector/.

WRAP (2008) WasteMinimisation Through Offsite TimberFrame Construction, Waste Resources and Action Programme.

Xiao, H. and Proverbs, D. G. (2003) 'Cost Certainty and Time Certainty: an International Investigation', Association of Researchers in Construction Management, 1(September), pp. 3-5. Available at: http://www.arcom.ac.uk/docs/proceedings/ar2003-023-032_Xiao_and_Proverbs.pdf.

Yang, L. R., O'Connor, J. T. and Chen, J. H. (2007) 'Assessment of automation and integration technology's impacts on project stakeholder success', Automation in Construction. doi: 10.1016/j.autcon.2006.11.005. 
Zhai, X., Reed, R. and Mills, A. (2014) 'Factors impeding the offsite production of housing construction in China: An investigation of current practice', Construction Management and Economics. doi: 10.1080/01446193.2013.787491.

Zhang, W., Lee, M.W., Jaillon, L. and Poon, C.S., 2018. The hindrance to using prefabrication in Hong Kong's building industry. Journal of cleaner production, 204, pp.70-81.

Zhao, X., Flynn, B. B. and Roth, A. V. (2006) 'Decision sciences research in China: A critical review and research agenda - Foundations and overview', Decision Sciences. doi: 10.1111/j.1540-5414.2006.00135.x. 